Pediat. Res. 13: 704 (1979)

\title{
Moderator's Introduction
}

\author{
BETTY BUMPERS
}

National League for Nursing, Consumer Advocate, Washington, D.C., USA

One of the most memorable days of my life was in the 1950's, when my husband and I, along with hundreds of thousands of parents all over the country, marched our children down to the local clinics where they were given a polio vaccine.

I remember the air of confidence and gratitude that the people exhibited toward the medical profession in this country and the government for assuming the responsibility of helping them cope with a health problem with which they were helpless in dealing. I remember, too, as an elementary teacher during the 50's, children coming to school early in the spring with high fevers, rashes, runny noses, red eyes, and coughs; the beginnings of measles epidemics, rubella, or whooping cough.

I also recall several cases of rubella syndrome children in my small community of 1400 children in Charleston, and taking my fourth grade students on a field trip to our State School for the Deaf, where I discovered that a very high percent of the school's children were there because they had contracted one of the preventable childhood diseases. These flashbacks took only a few seconds, and that's how long it took me to enthusiastically endorse a campaign to raise the levels of immunizations against childhood infectious diseases in the State of Arkansas.

In 1972, while my husband was governor of Arkansas, the Center for Disease Control asked me to help in alerting the people of Arkansas to the low levels of immunizations for the preventable childhood diseases. Since that time, Arkansas' Immunization Program has become a model for the rest of the country. Since 1974, reported cases of measles in Arkansas have been nonexistent or very low. Also, within 1 year, more than 100 thousand children were given over 400 thousand immunizations, and the immunity level for polio was raised from $50-80 \%$.

These successes and others are due, in part, to the enthusiastic support of the Arkansas League for Nursing, the Arkansas State Health Department, local government officials, volunteer agencies, the Department of Education, the Agricultural Extension Division of the US Department of Agriculture, the National Guard and many other interested citizens.

The most effective way to implement a successful immunization program is to work in concert with local leadership. I believe, as does Dr. James E. Bowes, President of End Measles, Inc., who has stated that the Federal Government can provide scientific advice and valuable assistance when called upon by the state, but the responsibility lies in the hands of state and local officials who have the authority to move the health dispensers, the local health officers, to conduct more clinics, and to get more children immunized.

Strictly enforced laws requiring evidence of complete immunization as a requirement of matriculation is an effective means of insuring immunization of school-age children.

Vaccine quality is the same whether received at a state-financed clinic or by a private practicing physician. Both modes of administration should be utilized and made available to the public. One of the things our children have a right to expect as part of their heritage is a healthy future. 